\title{
Fatty Acid Profile and Physicochemical Properties of Landolphia owariensis P. Beauv Stringy Seed Oil
}

\author{
Tochukwu JN Okonkwo ${ }^{1 *}$, Wilfred O Obonga ${ }^{2}$ and Chinedu JO Okonkwo ${ }^{3}$ \\ ${ }^{1}$ Pharmaceutical and Medicinal Chemistry Department, Faculty of Pharmaceutical Sciences, University of Port Harcourt, Port \\ Harcourt, ${ }^{2}$ Pharmaceutical and Medicinal Chemistry Department, Faculty of Pharmaceutical Sciences, University of Nigeria, \\ Nsukka, ${ }^{3}$ Biochemistry Department, Faculty of Chemical Sciences, College of Science, University of Port Harcourt, Port \\ Harcourt, Nigeria
}

*For correspondence: Email: tjokonkwo@yahoo.com; Tel: +234-(0)-806-710-1645

Received: 20 February 2014

Revised accepted: 23 June 2014

\begin{abstract}
Purpose: To elucidate lipid profile of Landolphia owariensis P. Beauv stringy seed oil, the bulk physicochemical properties of its neutral lipid (NL), and also to ascertain its nutritional properties, safety and industrial applications.

Methods: The neutral lipid was recovered by macerating $500 \mathrm{~g}$ of $\mathrm{L}$. owariensis stringy seed pulp in $1 \mathrm{~L}$ of petroleum ether $\left(40-60{ }^{\circ} \mathrm{C}\right.$ boiling range) for $48 \mathrm{~h}$. Methyl esters of the inherent fatty acids were generated by transmethylation while the physicochemical properties of the NL was determined by official methods of the Association of Official Analytical Chemists (AOAC).

Results: The acid, iodine, saponification and peroxide values were $2.81 \pm 0.01 \mathrm{mg} \mathrm{KOH} / \mathrm{g}, 67.26 \pm 1.05$ $\mathrm{mg} \mathrm{l} / 100 \mathrm{~g}, 219.38 \pm 2.69 \mathrm{mg} \mathrm{KOH} / \mathrm{g}$ and $6.00 \pm 0.28 \mathrm{mEq} / \mathrm{kg}$, respectively. Thiobarbituric acid reactive substance (TBARS) value $(6.10 \pm 0.24 \mathrm{mg} \mathrm{MDA} / \mathrm{kg})$ of the NL further confirmed the stability of NL (neutral lipid) against oxidative rancidity. Gas chromatographic analysis of the methyl ester mix of $L$. owariensis stringy seed pulp NL indicate hexadecanoic acid (palmitic acid) as the principal fatty acid with an absolute proportion of $54.38 \%$. Palmitoleic acid (18.54\%) and linoleic acid $(9.56 \%)$ ranked second and third, respectively, while the saturated/unsaturated fatty acid ratio was 2.53.

Conclusion: The neutral lipid of seed oil exhibited strong stability to ketonic and oxidative rancidity, and is safe for edible purposes. Its relatively high unsaturated fatty acid proportion $(28.29 \%)$ indicates that L. owariensis stringy seed pulp fixed oil possesses good nutritional qualities.
\end{abstract}

Keywords: Landolphia owariensis, Stringy seed pulp, Lipid profile, Fatty acids, Palmitic acid, Palmitoleic acid, Linoleic acid

Tropical Journal of Pharmaceutical Research is indexed by Science Citation Index (SciSearch), Scopus, International Pharmaceutical Abstract, Chemical Abstracts, Embase, Index Copernicus, EBSCO, African Index Medicus, JournalSeek, Journal Citation Reports/Science Edition, Directory of Open Access Journals (DOAJ), African Journal Online, Bioline International, Open-J-Gate and Pharmacy Abstracts

\section{INTRODUCTION}

Neutral lipids (NLs) are important elements in human nutrition. Apart from reducing the bulkiness of foods in the mouth, NLs are essential in the bio-synthesis of corticoids and steroidal hormones. Dietary, unsaturated fatty acids are essential for optimum health; as they are endogenous precursors of membrane polyunsaturated fatty acids (PUFs) and eicosanoids - which comprised of prostaglandins, prosthacyclins, leukotrienes and thromboxanes. Fatty acids, sourced from NLs, are as well important bio-energy molecules, and at times play leading roles in the reduction of body cholesterol levels; as indicated by omega-3 fatty acids. Furthermore, fatty acids are important matrix in drug delivery and targeting [1]. 
Plants are the major suppliers of fatty acids, as their neutral lipids consisted mainly of fatty acids. The neutral lipids of many tropical plants are under exploited [2], because their fatty acid profiles and bulk (physicochemical) properties are yet to be fully elucidated [3]. The scenario became worsened, as the specific applications of lipids depend exclusively on their fatty acid profiles and bulk properties. Thus accelerated elucidation of lipid properties became imperative. This need cannot be over emphasized, as it is pivotal to the development of economical and sustainable schemes for the exploitation and utilization of plant-derived lipids.

Landolphia owariensis $\mathrm{P}$. Beauv is native to Africa and is economically important for latex/rubber and folklore medicine $[4,5]$. It is commonly known as white rubber vine or vine rubber, and is widely used in the treatment of many ailments. Vast majority of its ethno pharmacological uses have been documented [6-11].

The folkloric use of $L$. owarienisis as antimicrobial agent has been validated [12-14]. Its other medicinal and nutritional uses have as well been confirmed [2,5,15-17]. Akubugwo and Ugbogu reported the physicochemical properties of Landolphia owariensis seed oil [18].

In our continued, efforts to highlight the medicinal, nutritional and industrial potential of $L$. owariensis P. Beauv. [19,20], schematic procedures were adopted to elucidate the fatty acid profile of its stringy seed pulp. Because, LOSP is freely eaten by plants and animals from time immemorial. The findings should be in ascertaining the risk/benefit ratio of $L$. owariensis as well as its possible industrial applications.

\section{EXPERIMENTAL}

\section{L. owariensis stringy seed pulp}

The seeds of Landolphia owariensis P. Beauv were collected in March 2007, and authenticated by $\mathrm{Mr}$ CA Ugwuozor of the Department of Botany, University of Nigeria, Nsukka, Nigeria. A voucher specimen (no. UNH/133) was deposited at the department's herbarium. $L$. owariensis seeds were air-dried at ambient temperature and the stringy seed pulp separated and pulverized to a fine powder. Landolphia owariensis $\mathrm{P}$. Beauv stringy seed pulp (LOSP) was macerated in 1.00 $\mathrm{L}$ of petroleum spirit $\left(40-60^{\circ} \mathrm{C}\right)$ for $48 \mathrm{~h}$. The extract was dried in vacuo at less than $40{ }^{\circ} \mathrm{C}$ in a rotating evaporator. The neutral lipid (petroleum spirit extract) of the stringy seed pulp was used to prepare methyl esters.

\section{Preparation of LOSP methyl ester (Trans- esterification)}

Two grams of the neutral lipid was transferred into a volumetric flask, dissolved in $50 \mathrm{ml}$ chloroform and made up to $100 \mathrm{ml}$ with more aliquots of chloroform. The chloroform solution was evaporated at room temperature to near dryness and the residue, re-dissolved in $1 \mathrm{ml}$ of trans-esterification reagent (equi-volume mixture of $20 \%$ benzene and $55 \%$ methanol). The reaction mix was placed in a sealed round bottom flask and heated at $100{ }^{\circ} \mathrm{C}$ in a water bath for $30 \mathrm{~min}$. After trans-esterification, $2 \mathrm{ml}$ of a 1:1 mixture of $n$-hexane and water was added into the reaction bath and shaken vigorously for 2 min to extract the methyl esters. The extract was centrifuged, and $0.5 \mathrm{ml}$ of the $\mathrm{n}$-hexane phase transferred into a test tube for GC analyses.

\section{Specific gravity}

A dried and tarred $50 \mathrm{ml}$ pyrometer bottle was filled with distilled water and weighed. The water was discharged and the bottle dried; after which it was filled with LOSP neutral lipid and weighed. The specific gravity $(\mathrm{Sg})$ of LOSP neutral lipid was evaluated as the ratio of the weight of $50 \mathrm{ml}$ of NL to the weight of an equal volume of water.

\section{Refractive index}

The oil sample was smeared on the lower prism of an Abbe refractometer with a compensator (water at $20^{\circ} \mathrm{C}$ ), a light passed by the angled mirror was made incident on the sample and the reflected light appeared in a form of a dark background. Using the fine adjustment, the telescope tubes was moved until black shadow appeared central in the cross wire indicator. Then, the refractive index was read off.

\section{Flash point}

A $10 \mathrm{ml}$ aliquot of LOSP NL was placed in an evaporating dish and a thermometer suspended at the centre of the dish with the bulb deeping into the oil without touching the bottom of the dish. The temperature of the oil was raised; and the temperature at which the oil started flashing on to the thermometer stem, without supporting combustion was recorded as the flash point.

\section{Free fatty acid (FFA) value}

One mililitre of $1 \%$ phenolphthalein solution (in $50 \%$ aqueous alcohol) was added to $50 \mathrm{ml}$ equi- 
volume mixture of diethyl ether and alcohol, and the reagent carefully neutralized with $0.1 \mathrm{M} \mathrm{KOH}$. Two gram of LOSP NL was dissolved in $20 \mathrm{ml}$ of the neutral mixed solvent and titrated with $0.1 \mathrm{M}$ $\mathrm{KOH}$ to a persistent light pink end-point. The FFA value $(\mathrm{mgKOH} / \mathrm{g})$ was evaluated as in Eq 1.

FFA value $=5.61 \mathrm{~T} / \mathrm{W}$

where $T$ is the titer (in $\mathrm{mL}$ ) and $\mathrm{W}$ is the weight of the of the sample.

\section{Acid value}

The acid value of LOSP NL was evaluated as 2(FFA).

\section{Saponification value}

Two grams of LOSP NL was dissolved in $25 \mathrm{ml}$ of $0.5 \mathrm{M}$ alcoholic $\mathrm{KOH}$, and transferred completely into a round bottom flask with ground glass joint. The reflux condenser was attached, and the reaction system heated for $1 \mathrm{~h}$ in boiling water bath with continuous stirring. One $\mathrm{ml}$ of 1 $\%$ phenolphthalein was added to the reaction mix, and the system titrated hot against $0.5 \mathrm{M}$ hydrochloric acid. A blank titration was done, and the saponification value (Sv) deduced as as in Eq 2.

Sv $=\{(b-a) 28.05\} /($ weight of sample $)$ where $b$ and $a$ are the respective titre values of the blank and test titrations.

\section{Saponification equivalent}

Saponification equivalent (Seq) is an index of the average acyl chain of lipids. It could be, loosely, taken to denote the average molecular weight of fatty acid mix of any neutral lipid. That is, it indicates the major fatty acid of fats and oils. Mathematically, it is related to saponification value as in Eq 3.

Seq $=56100 /$ saponification value

\section{lodine value}

Two grams of LOSP NL was dissolved in $10 \mathrm{ml}$ of carbon tetrachloride and transferred into a glass-stoppered bottled. Thereafter, $20 \mathrm{ml}$ of Wiji's solution was poured into the bottle, the stopper replaced (which was previously moistened with potassium iodide solution) and allowed to stand in the dark for $30 \mathrm{~min}$ with intermittent shaking. After 30 mins, $15 \mathrm{ml}$ of $10 \%$ potassium iodide solution and $100 \mathrm{ml}$ of distilled water was added; and the system titrated against $0.1 \mathrm{M}$ thiosulphate solution using starch indicator. A blank titration was carried out, and the iodine value (Iv, $\mathrm{mg} \mathrm{I} / 100 \mathrm{~g}$ ) evaluated as in Eq 4.

IV $=\{(a-b) 1.269\} /$ sample weight

where $b$ and $a$ are the respective titre values of blank and test titrations.

\section{Peroxide value}

One gram of LOSP NL was weighed into a boiling tube, followed by addition of $1 \mathrm{~g}$ of $\mathrm{KI}$ and $20 \mathrm{ml}$ of 2:1 (v/v) glacial acetic acid/chloroform mixture. The tube was placed in a boiling water bath such that the content boiled within $30 \mathrm{~s}$, and continued boiling vigorously for more than $30 \mathrm{~s}$. The reaction mix was quickly transferred into a flask containing $20 \mathrm{ml}$ of $5 \% \mathrm{Kl}$ solution, and the boiling tube rinsed twice with $25 \mathrm{ml}$ of distilled water, each time. Using starch indicator, the system was titrated against $0.002 \mathrm{M}$ sodium thiosulphate solution. A blank titration was carried out, and peroxide value $(\mathrm{mEq} / \mathrm{kg})$ computed as in Eq 5.

Peroxide value $=(a-b) 2$

where $a$ and $b$ are titre value (expressed in $\mathrm{ml}$ ) for test and blank titration.

\section{Thiobarbituric acid (TBA) number/value}

Ten gram of LOSP was macerated in $50 \mathrm{ml}$ of distilled water for $2 \mathrm{~min}$, and washed into a distillation flask containing $47.5 \mathrm{ml}$ of distilled water. After which, the $\mathrm{pH}$ was adjusted to 1.5 with $2.5 \mathrm{ml}$ of conc. $\mathrm{HCl}$, and antifoam and antibump were added. The flask was heated in an electric mantle $50 \mathrm{ml}$ of its content within the first $10 \mathrm{~min}$ of boiling. A 5-ml aliquot of the distillate was transferred into a glass-stoppered tube, and then $5 \mathrm{ml}$ of TBA reagent $(0.2883 \mathrm{~g}$ TBA $/ 100 \mathrm{ml}$ $90 \%$ glacial acetic acid) was added, shaken and heated in boiling water for 35 min. A blank was similarly prepared with $5 \mathrm{ml}$ of distilled water, against $5 \mathrm{ml}$ of the distillate. Both tubes were cooled in water for $10 \mathrm{~min}$, and the visible light absorbance (A) of the test solution measured against the blank at $538 \mathrm{~nm}$. Thiobarbituric acid reacting substance (TBARS, mg MDA/kg) was evaluated as Eq 6.

TBARS $=7.8^{*} \mathrm{~A}$

where MDA denotes malondialdehyde and $A$ is the absorbance of the test solution.

\section{Viscosity, conductivity and $\mathrm{pH}$ determination}

The viscosity, conductivity and $\mathrm{pH}$ of LOSP NL were determined with viscometer, conductivity meter and $\mathrm{pH}$ meter, respectively. The instruments were calibrated, as stated in the 
respective manufacturer's manual, before taking measurements.

\section{GC analysis of LOSP methyl esters}

Agilent 6890 gas chromatograph equipped with an on-column automatic injector, flame ionization detector, HP 88 capillary column $(100 \mathrm{~m} \times 0.25$ $\mu \mathrm{m}$ film thickness) was used for the GC analyses. Injection temperature was maintained at $220{ }^{\circ} \mathrm{C}$ with an integrator chart speed of 2 $\mathrm{cm} / \mathrm{min}$, while the detector operated at $250{ }^{\circ} \mathrm{C}$. The column oven temperature was set at $180^{\circ} \mathrm{C}$ and maintained constantly at 15 -min analysis period. One microlitre of the sample was injected onto the column, eluted and the chromatogram recorded as per cent relative intensity against elution peak. The identity of the eluted peaks was obtained by matching against the retention parameter of a standard mixture of methyl esters.

\section{Statistical analysis}

Where applicable, results were expressed as mean \pm SEM. Means were compared for statistical significant difference by one-way analysis of variance (ANOVA) using Duncan post-hoc test with the aid of GraphPad Prism $®$ statistical software version 5.0. Effects were considered significant at $p<0.05$ in all cases.

\section{RESULTS}

Table 1 shows the physicochemical properties of LOSP NL. The table indicated that the average molecular weight of LOSP NL corresponds to the dominance of palmitic acid in neutral lipids. Table 2 presents the fatty acid profile of LOSP NL.

\section{DISCUSSION}

The relatively high smoke and flash points of the lipid indicated that the acyl chains of LOSP NL fatty acids are of long saturated carbon chains. This was confirmed by the solid physical state of the lipid at room temperature. Since long chain saturated fatty acids, are usually solids at room temperature. Thus the lipid will express high thermal stability; and will serve effectively as cooking (frying) oil with low potential to yield low molecular weight carcinogenic pyrolysis products.

Table 1: Physicochemical properties of LOSP NL

\begin{tabular}{lc}
\hline Parameter & Test value \\
\hline Specific gravity & $0.92 \pm 0.01^{*}$ \\
Refractive index & $1.52 \pm 0.03^{*}$ \\
Smoke point $\left({ }^{\circ} \mathrm{C}\right)$ & $55.00 \pm 0.87$ \\
Flash point $\left({ }^{\circ} \mathrm{C}\right)$ & $85.00 \pm 1.01$ \\
Viscosity $(\mathrm{pa} / \mathrm{s})$ & $1.54 \pm 0.12$ \\
Conductivity $(\mu \mathrm{s} / \mathrm{cm})$ & $137.40 \pm 1.57^{*}$ \\
$\mathrm{pH}$ & $6.60 \pm 0.06^{*}$ \\
FFA value $(\mathrm{mgKOH} / \mathrm{g})$ & $1.40 \pm 0.01$ \\
Acid value $(\mathrm{mgKOH} / \mathrm{g})$ & $2.81 \pm 0.01$ \\
Saponification & $219.38 \pm 2.69^{*}$ \\
(mgKOH/g) & \\
Saponification equivalent & $255.72 \pm 2.62^{*}$ \\
lodine value (miliEqu.//100 g) & $67.26 \pm 1.05$ \\
Peroxide value (miliEqu./Kg) & $6.00 \pm 0.28$ \\
TBARS value (mgMDA/Kg) & $6.10 \pm 0.24$ \\
\hline *Significant at $p \leq 0.05$ &
\end{tabular}

*Significant at $p \leq 0.05$

The specific gravity $(\mathrm{Sg}), \quad 0.92 \pm 0.01$, lay between $0.90-0.94$; expected of neutral lipids. As Sg tends towards 0.90 , it appears that the fixed oil of LOSP constituted majorly of fatty acids of high mean molecular weight. This was confirmed by the saponification value, saponification equivalent and the GC chromatogram of LOSP NL. In this regard, the saponification equivalent approximately tallied with the molecular mass of palmitic acid; which was indicated as the dominant fatty acid by the GC chromatogram. The moderate iodine value of the neutral lipid indicated that it is non-drying oil. It is because, semi-drying and drying oils usually possessed iodine values much greater than 80 $\mathrm{mgl} / 100 \mathrm{~g}$. It further confirmed that LOSP NL glycerides and contain saturated acyl chains in high proportions.

Table 2: Fatty acid profile of LOSP NL and content of fatty acids

\begin{tabular}{|c|c|c|c|c|}
\hline Carbon chain & Fatty acid & $\begin{array}{c}\begin{array}{c}\text { Retention time } \\
(\mathrm{min})\end{array} \\
\end{array}$ & $\begin{array}{c}\text { Peak } \\
\text { height (cts) }\end{array}$ & $\begin{array}{c}\text { Content } \\
(\%)\end{array}$ \\
\hline C15 & Pentadecanoic acid & 12.3148 & 2060.49 & 1.85 \\
\hline C16:1 & Palmitoleic acid & 20.8408 & 20631.68 & 18.54 \\
\hline C16:0 & Palmitic acid & 26.6125 & 60519.72 & 54.38 \\
\hline C:10 & Capric acid & 35.9160 & 547.42 & 0.49 \\
\hline C:11 & Undecanoic acid & 39.4491 & 3788.48 & 3.41 \\
\hline C12 & Lauric acid & 42.4602 & 3962.08 & 3.56 \\
\hline C14 & Myristic acid & 45.7820 & 2156.65 & 1.93 \\
\hline C18:2 & Linoleic acid & 54.8729 & 11490.97 & 9.56 \\
\hline C17 & Heptadecanoic acid & 59.9773 & 1650.31 & 1.48 \\
\hline C18:3 & Linolenic acid & 65.8430 & 209.44 & 0.19 \\
\hline C18 & Stearic acid & 67.7085 & 5114.40 & 4.59 \\
\hline
\end{tabular}


Stability of LOSP NL, as measured by the peroxide, TBARS, free fatty acid and acid values, were quite high. In actual fact peroxide value is used to monitor the development of rancidity through the evaluation of the quantity of peroxide (initiation product of oxidative rancidity) generated in the lipid. During storage of most fats, the peroxide value shows little increase in the early stages, known as induction period, after which there is then a marked increase. Peroxide value of oil is a measure of its content of oxygen, and fresh oils usually have peroxide values below $10 \mathrm{mEqu} . / \mathrm{Kg}$. A rancid taste begins to show up when the peroxide value is between 20 and $40 \mathrm{mEqu} . / \mathrm{Kg}$.

TBA value/number estimates the amount of MDA present in a lipid sample. MDA has been demonstrated to be an end product of oxidative rancidity of neutral lipids; and reacts with TBA to produce red pigment that can be estimated spectrophotometrically. Thus low TBARS values indicate low rate of lipid peroxidation and high stability against oxidative rancidity.

FFA and acid values of lipids measure the extent to which the glycerides in neutral lipids have been decomposed by lipase action, releasing free fatty acids. The determination is often used as a general indication of the condition and edibility of oils. As rancidity is usually accompanied by free fatty acid formation; and values in excess of 2 and $4 \mathrm{mgKOH} / \mathrm{g}$, respectively, indicate ketonic rancidity. The $\mathrm{pH}$ of the sampled lipid revealed very weak acidity, which correlated well with the very low acid value of the sample. This further confirmed the stability of LOSP NL to enzymatic hydrolysis, could initiated by micro-organisms and inherent lipases in the neutral lipid.

Saponification value is inversely proportional to the mean molecular weight of fatty acids in the glyceride present. It indicates the potential of neutral lipids as raw materials in the manufacture of soapy detergents. As lipids with moderate to high saponification values are important raw materials in the manufacture of soapy detergents. The observed saponification value of LOSP NL is moderately high, expressing the ability of the neutral lipid to yield large amount of soap per unit weight.

The GC chromatogram of LOSP NL indicated a number of fatty constituents, out of which 11 were identified by standard comparison. It revealed hexadecanoic (palmitic) acid as the dominant fatty acid; while the mono-unsaturated
C16 fatty acid, palmitoleic ranked second in abundance. The doubly unsaturated $\mathrm{C} 18$ linoleic acid was, also, fairly abundant; representing third ranking in the relative fatty acid composition. Both unsaturated fatty acids are important elements in human and animal nutrition. As animal species are incapable synthesizing unsaturated fatty acids. Therefore, all their unsaturated fatty acid needs must be supplied in the diet. These fatty acids, otherwise known as essential fatty acids, are important precursors in the synthesis of bio-functional long chain polyunsaturated fatty acids, which are the building blocks of ecosanoids and phospholipds. Also, they play leading roles in the reduction of low density lipoprotein-cholesterol (LDL-cholesterol).

\section{CONCLUSION}

The findings obtained demonstrate that LOSP neutral lipid consists majorly of the long chain C16 saturated and unsaturated fatty acids, namely, palmitic and palmitoleic acids, respectively. Since its saturated/unsaturated fatty acid ratio of 2.53 indicates high proportion of unsaturated fatty acids, the lipid is recommended for use as food additive/nutriceutical for the mitigation of hypercholestemia.

\section{ACKNOWLEDGEMENT}

The authors are most grateful to $\mathrm{Mr}$ Alfred Ozioko, Bio-resources Development and Conservation Programme, Nsukka, Nigeria for collection of plant material.

\section{REFERENCES}

1. Okorie O, Okonkwo TJN, Nwachukwu N, Okeke I. Potentials of Detarium microcarpum (Guill and Sperr) Seed Oil as a Matrix for the Formulation of Haloperidol Injection. Int J Pharm Sci Rev \& Res 2010; 5(1): 1-4.

2. Ihekoronye Al, Ngoddy PO. Integrated Food Science and Technology for the Tropics. London: Macmillian Publishers Ltd, UK; 1985. pp. 82-93.

3. Okonkwo TJN, Okonkwo CJO. Antioxidant Properties of Diospyros preussi (Ebenaceae Gurke) Seed Oil. Trop J Pharm Res, 2009; 8(6): 551-555.

4. Pichon M. Monograhie des Landolphiees (Classification des Apocynacees, XXXV). Me Ins Franc Afrique Noire 1953; 35: 272-302.

5. Bolch N. Crops and rubbers. Earthwatch 1990; 10: 1421.

6. Bouquet A. Feticheur et Medicines Traditionelle du Congo (Brazzaville). Mem O R S T O M 1969; 32: 25-27. 
7. Gill LS. Ethnomedicinal uses of Plants in Nigeria. 1st Ed. Benin City: Uniben Press, 1992; $p 145$.

8. Lewis WH, Elvin-Lewis MP. Medical Botany. 1st Ed. New York: John Wiley and Sons, 1977; pp. 21-22.

9. Irvine FR. The Woody Plants of Ghana. 2nd Ed. London: Oxford University Press, 1961; pp 26-28.

10. Anthony CB. Natural Preservatives from Landolphia owariensis. Afr Dev J 1995; 2: 21-22.

11. Dalziel JM. Useful Plants of West Tropical Africa. 2nd Ed. London: Crown Agents for the colonies, 1937. p. 374.

12. Ebi GC, Ofoefule SI. Investigation into the Folkloric Antimicrobial Activities of Landolphia owariensis. Phytother Res 1997; 11: 149-151.

13. Okeke MI, Iroegbu CU, Eze EN, Okoli AS, Esimone CO. Evaluation of Extracts of the Roots of Landolphia owarrience for Antimicrobial Activity. J Ethnopharmacol 2001; 78: 119-127.

14. Nwogu LA, Alisi CS, Ibegbulem CO, Igwe CU. Phytochemical and Antimicrobial Activity of Ethanolic Extract of Landolphia owariensis leaf. Afr J Biotech 2007; 6: 890-893.

15. Owoyele BV, Olaleye SB, Oke JM, Elegde RA. Antiinflammatory and Analgesic Activities of Leaf Extract of Landolphia owariensis. Afr J Biomed Res 2001; 4: 131-133.

16. Oke JM, Hamburger MO. Screening of some Nigerian Medicinal Plants for Antioxidant Activity using 2, 2 diphenyl-picryl-hydrazyl radical. Afr J Biomed Res 2002; 5: 77-79.

17. Olaleye SB, Owoyele VB, Odukanmi AO. Antiulcer and Gastric Antisecretory Effects of Landolphia owariensis Extracts in Rats. Niger J Physiol Sci 2008; 23(1-2): 23-26.

18. Akubugwo IE, Ugbogu AE. Physicochemical Studies on Oils from Five Selected Nigerian Seeds. Pak J Nutr 2007; 6: 75-78.

19. Okonkwo TJ, Osadebe PO. Hepatoprotective Effect of Landolphia owariensis P. Beauv Seed against CCl4induced Hepatopathy in Rats. Port Harcourt Med J 2010; 4: 307-312.

20. Okonkwo TJN, Osadebe PO. Isolation and Characterization of Potential Bioactive Compounds from Landolphia owariensis $P$. Beauv Stringy Seed Pulp. Int J Appl Res Nat Prod 2013; 6(3): 28-38. 